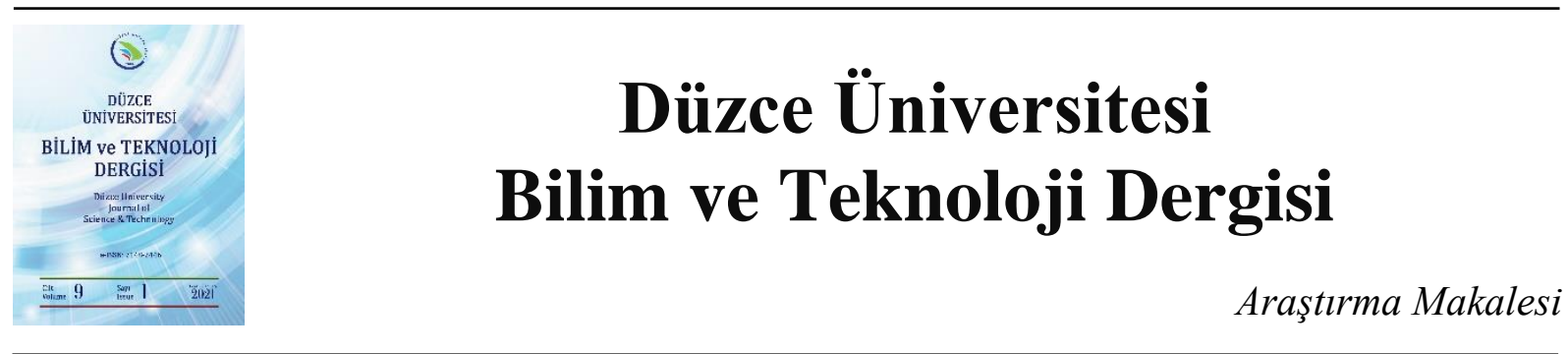

\section{Nokta Direnç Kaynağı ile Birleştirilen DP1200 Çeliğinin Dayanımı Üzerinde Kaynak Parametrelerinin Etkisinin İstatistiksel Analizi}

\author{
Muhammed ELITAŞ ${ }^{\mathrm{a}}{ }^{*}$ \\ ${ }^{a}$ Makine Mühendisliği Bölümü, Mühendislik Fakültesi, Bilecik Şeyh Edebali Üniversitesi, Bilecik, TÜRKIYYE \\ * Sorumlu yazarın e-posta adresi: muhammed.elitas@bilecik.edu.tr
} DOI : 10.29130/dubited.790026

\begin{abstract}
ÖZET
Bu çalışmada nokta direnç kaynaklı DP1200 çeliğinin ideal çekme makaslama dayanımını elde etmek için farklı kaynak akımı ve elektrot basıncı parametrelerinin optimizasyonuna odaklanılmıștır. Kaynak prosesleri 5 kA ve 7 kA kaynak akımlarında, 2-6 bar elektrot basınçlarında gerçekleştirilmiştir. Kaynak parametrelerinin çekme makaslama dayanımı üzerindeki etkileri çoklu doğrusal regresyon analizi ile incelenmiştir. Yapılan bu analiz ile elde edilen korelasyon tablosu ve ANOVA analiz değerleri yorumlanmıştır. Kaynak parametrelerinin önem derecesi belirlenerek, çekme makaslama dayanımı üzerindeki etkileri karşılaştııılmış ve belirlenen etki değerlerine göre çoklu doğrusal regresyon modeli oluşturulmuştur. Deneysel sonuçlar çekme makaslama dayanımını etkileyen en önemli değişkenin kaynak akımı olduğunu göstermiştir. Kaynak akımı arttıkça çekme makaslama dayanımı artmışırı. Özellikle yüksek kaynak akımı değerinde, elektrot basıncının kritik değerine kadar çekme makaslama dayanımının arttığı, fakat kritik değerinin üzerinde dayanımda düşüş olduğu görülmüştür. Sıçramanın çekme makaslama dayanımı üzerinde negatif etkiye sahip olduğu gözlenmiştir.
\end{abstract}

Anahtar Kelimeler: DP1200 çeliği, Nokta direnç kaynă̆ı, Regresyon analizi, Çekme makaslama dayanımı, Siçrama

\section{Statistical Analysis of the Effect of Welding Parameters on the Strength of DP1200 Steel Combined with Resistance Spot Welding}

\begin{abstract}
In this study, focused on optimization of different welding current and electrode pressure parameters to obtain the ideal tensile shear strength of resistance spot welded DP1200 steel. Welding processes were carried out at 5 $\mathrm{kA}$ and $7 \mathrm{kA}$ welding currents and 2-6 bar electrode pressures. The effects of welding parameters on tensile shear strength were investigated by multiple linear regression analysis. The correlation table and ANOVA analysis values obtained with this analysis were interpreted. The importance of the welding parameters was determined, their effects on the tensile shear strength were compared and a multiple linear regression model was created according to the determined effect values. Experimental results showed that welding current is the most important variable affecting tensile shear strength. As the welding current increased, the tensile shear strength increased. Especially at high welding current values, it was observed that the tensile shear strength increased until the critical value of the electrode pressure, but there was a decrease in the strength above the critical value. It was observed that expulsion has a negative effect on tensile shear strength.
\end{abstract}

Keywords: DP1200 steel, Resistance spot welding, Regression analysis, Tensile shear strength, Expulsion 


\section{GIRIS}

Otomobillerde yakıt verimliliği için artan talepler yeni yapısal malzemelerin düşünülmesine neden olmaktadır. Yeni malzemeler, özellikle dayanımlarının çok iyi olması ve aracın ağırlığını azaltabilmesi bakımından düşünülmektedir. Aracın ağırlığını azaltmak ise yakıt tüketimini azaltacağı için çok önemlidir. Bu bakımdan alüminyum alaşımları ve geliştirilmiş yüksek mukavemetli çelikler (AHSS), mevcutta kullanılan düşük karbonlu çeliklere ve HSLA çeliklerine alternatif olarak araştırılmaktadır. Alüminyum alaşımlarının çeliklere göre üçte bir yoğunluğu olmasına rağmen otomobillerde kullanımı sınırlıdır. Çünkü daha yüksek maliyete sahip olması ve şekillendirme, kaynak edilme gibi imalat işlemlerinin zor olması kullanımını sınırlandırmaktadır [1].

AHSS; enerji korunumu, emniyet gelişimi ve çarpışma dayanımı özelliklerini sağlamak için otomotiv endüstrisinde hafif araç tasarım stratejileri için anahtar malzemelerdir [2], [3]. Direkler, yan eşikler, külbütörler, kapı takviye kirişleri, tavan rayları ve taban ve tavan çapraz elemanlarından oluşan aracın güvenlik kafesindeki yapısal takviye bileşenleri, $1 \mathrm{GPa}$ değerinden daha fazla çekme dayanımlı çelikler gerektirir. Bu yüzden AHSS, bu bileşenlerde kullanım için en iyi gelecek vaat eden çeliklerden biridir [4], [5].

Malzemenin mikroyapı, mekanik özelliklerine ve uygulanan işleme göre AHSS çeşitli sınıflara ayrılmaktadır. En genel kullanılan sınıflandırma ise çift fazlı (DP), TRIP ve ferritik-beynitik (FB) çeliklerdir [6]. AHSS, geleneksel yüksek mukavemetli çeliklere göre daha yüksek akma dayanımına ve daha düşük akma/çekme dayanımı oranına, iyi şekillendirilebilme kabiliyetine, yüksek çalışma sertliği oranına ve yüksek gerinim enerjisi absorbe edebilme kabiliyetine sahiptir [7]. Bu bağlamda, AHSS ağırlık azalımı, emniyetli performans gelişimi ve maliyet kazanımı gibi avantajlarından dolayı otomotiv endüstrisinde kullanılmaktadır [8]. AHSS tavlama sonrası soğutma işlemi uygulanarak düşük sıcaklıkta östenit dönüşümü ile elde edilmektedir. Farklı alaşım elementleri ve soğutma işlemlerine bağlı olarak AHSS farklı mikroyapıya sahip olmaktadır [7], [9].

AHSS arasında DP çelikleri, otomobil üreticileri tarafından en geniş kullanıma sahip düşük alaşımlı çeliklerdir [10]. DP çeliklerinde karbon oranı genel olarak \%0,05-0,2 aralığında ve mangan oranı $\% 1,5$ 'ten fazladır [11]. DP çelikleri; şase, tekerlek, tampon gibi otomotiv parçalarında yüksek dayanım ve süneklik özelliklerinden dolayı sıklıkla kullanılmaktadır. Bu özellikler; kritik tavlama sonrası soğutma işlemi uygulanarak elde edilen ferrit ve martensit yapı ile sağlanmaktadır [12], [13]. Östenit fazından martensit fazına dönüşüm boyunca hacimsel yayılım, ferritik matriste hareketli dislokasyonların oluşumuna neden olmaktadır. Bu doğrultuda birbirleri ve faz sınırları ile temasları sonucunda yüksek gerinim sertleşmesi oranı ve sürekli deformasyon davranışı görülmektedir [14][16]. Sonuçta geleneksel veya HSLA çeliklerine göre daha yüksek toplam uzama, daha yüksek çekme dayanımı, daha düşük akma dayanımı/çekme dayanımı oranı sağlamaktadır. Bu avantajları DP çeliklerini otomotiv uygulamaları için cazip kılmaktadır [17].

Otomotiv endüstrisinde özellikle DP çelikler için kilit birleştirme prosesi olan nokta direnç kaynağ1 (NDK), araç üretiminde kritik rol oynar [18]. Araç gövdesi, aracın boyutuna ve bir araya getirilmesi gereken parçaların sayısına ve üreticinin birleştirme stratejisine bağlı olarak 3000-5000 nokta kaynaklı bağlantı içerir [19]. Kaza durumunda yaralanmalara karşı yolculara yeterli koruma sağlamak için araç yapısının kabiliyeti olarak tanımlanan araç çarpışma dayanımı, nokta direnç kaynaklarının entegrasyonuna ve mekanik performansına büyük ölçüde bağlıdır [20], [21]. Bu yüzden, çarpışma sırasında yük transferi ve enerji dağılımını maksimize etmek için nokta kaynaklarının yüksek yük taşıma kapasitesi ve yüksek enerji absorbe kabiliyetine sahip olmasına ihtiyaç duyulur [22]. Bu doğrultuda, en uygun çekme makaslama dayanımı değerini elde etmek için ideal kaynak parametrelerini seçmek önemlidir. Ayrıca kaynak parametrelerinin çekme makaslama dayanımı üzerindeki önem derecesinin belirlenmesi çok önemlidir. Literatürde bu konu ile ilgili bazı çalışmalar bulunmaktadır. Eshraghi vd. [23] sonlu elemanlar analizi temelli bir model ile farklı kaynak parametrelerinin DP600 çeliğinin farklı kaynak özellikleri üzerindeki etkisini araştırmışlardır. Tüm kaynak parametreleri içerisinde kaynak akımının en etkili faktör olduğunu tespit etmişlerdir. Thakur 
ve Nandedkar [24] galvanizli çeliklerin nokta direnç kaynakları için farklı kaynak proses parametrelerinin çekme makaslama dayanımı üzerindeki etkisini belirlemek için sistematik bir yaklaşım sunmuşlardır. $\mathrm{Bu}$ doğrultuda istatistiksel analizler yardımıyla nokta direnç kaynak performansını etkileyen en önemli parametreleri tespit etmişlerdir. Eşme vd. [25] nokta direnç kaynaklı SAE1010 çeliğinde kaynak parametrelerinin değişiminin dayanıma etkilerini incelemişlerdir. Sonuç olarak, kaynak dayanımına etki eden en önemli değişkenlerin sırasıyla elektrot basıncı, elektrot çapı, kaynak akımı ve kaynak zamanı olduğunu ifade etmişlerdir. X.Q. Zhang vd. [26] kaynak akımlarının kaynak zamanına göre kaynak dayanımı üzerindeki etkisinin daha fazla olduğunu belirtmiştir. Fakat daha düşük akımlarda daha yüksek akımlara göre kaynak süresinin kaynak dayanımı üzerinde daha büyük bir etkiye sahip olduğunu belirtmişlerdir. Aydin [27] otomotiv uygulamaları için DP600 ve DP1000 farklı nokta direnç kaynak birleşimlerinde farklı kaynak akımlarının mekanik özellikler üzerindeki etkisini araştırmıştır. Sonuç olarak kaynak akımı artışına bağlı olarak çekme makaslama dayanımının arttığını ifade etmiştir. Luo vd. [28] geliştirilmiş yüksek mukavemetli çeliklerin ve yüksek mukavemetli çeliklerin nokta direnç kaynaklı birleşimlerinin mekanik özellikleri üzerinde kaynak zamanı ve elektrot basıncının etkilerini incelemiş̧lerdir. Thakur vd. [29] nokta direnç kaynaklı galvanizli çeliklerde kaynak parametrelerinin optimizasyonunun çekme makaslama dayanımı üzerindeki etkisini araştırmışlardır.

$\mathrm{Bu}$ çalışmada özellikle otomotiv endüstrisinde AHSS çelikleri içerisinde en sık kullanıma sahip DP çelikleri arasından DP1200 çeliği incelenmiştir. Literatürde gerçekleştirilen çalışmalar incelendiğinde DP1200 çeliğinin mekanik özellikleri üzerinde NDK prosesinin etkisi ile ilgili çalışmaya rastlanmamıştır. Özellikle DP600, DP780, DP1000 çelikleri üzerine yoğunlaşılmıştır. Bu çalışma, literatürde bu DP derecesi ile ilgili boşluğu doldurması bakımından önem arz etmektedir. Arzu edilen özelliklerde kaynak elde edebilmek için ideal kaynak parametrelerinin belirlenmesi çok önemlidir. Bu çalışmada DP1200 çeliğinin NDK işleminde ideal çekme makaslama dayanımını sağlamak için farklı kaynak akımı ve elektrot basıncı parametrelerinin optimizasyonuna odaklanılmıştır. Ayrıca kaynak parametrelerinin çekme makaslama dayanımı üzerine etkisi IBM SPSS STATISTICS 22.0 programında çoklu doğrusal regresyon analizi ile incelenmiştir. Yapılan bu analiz ile elde edilen korelasyon tablosu ve ANOVA analiz değerleri yorumlanmıştır. Kaynak parametrelerinin önem derecesi belirlenerek, çekme makaslama dayanımı üzerindeki etkileri karşılaştııılmış ve belirlenen etki değerlerine göre çoklu doğrusal regresyon modeli oluşturulmuştur.

\section{DENEYSEL CALISSMALAR}

Bu çalışmada NDK ile birleştirilmiş DP1200 çeliği incelenmiştir. Çeliğin kimyasal bileşimi spektral analiz gerçekleştirilerek belirlenmiş ve elde edilen sonuçlar Tablo 1'de gösterilmiştir. Faz oranları görüntü analizi gerçekleştirilerek tespit edilmiştir. DP1200 çeliğinin düşük miktarda ferrit (\%15) ve ağırlıklı olarak martensit fazından (\%85) oluşan mikroyapısı ise Şekil 1'de gösterilmiştir. Numunelerin sac kalınlığ 1 mm'dir.

Tablo 1. DP1200 çeliğinin kimyasal bileşimi.

\begin{tabular}{cccccccc}
\hline \multicolumn{7}{c}{ Kimyasal bileşim (\%) } \\
\hline $\mathbf{C}$ & $\mathbf{S i}$ & $\mathbf{M n}$ & $\mathbf{P}$ & $\mathbf{S}$ & $\mathbf{C r}$ & $\mathbf{N i}$ & $\mathbf{A l}$ \\
0,078 & 0,190 & 1,67 & 0,005 & 0,005 & 0,026 & 0,040 & 0,044 \\
\hline $\mathbf{C o}$ & $\mathbf{C u}$ & $\mathbf{N b}$ & $\mathbf{T i}$ & $\mathbf{V}$ & $\mathbf{S n}$ & $\mathbf{F e}$ & \\
0,021 & 0,013 & 0,004 & 0,036 & 0,010 & 0,002 & 97,856 & \\
\hline
\end{tabular}




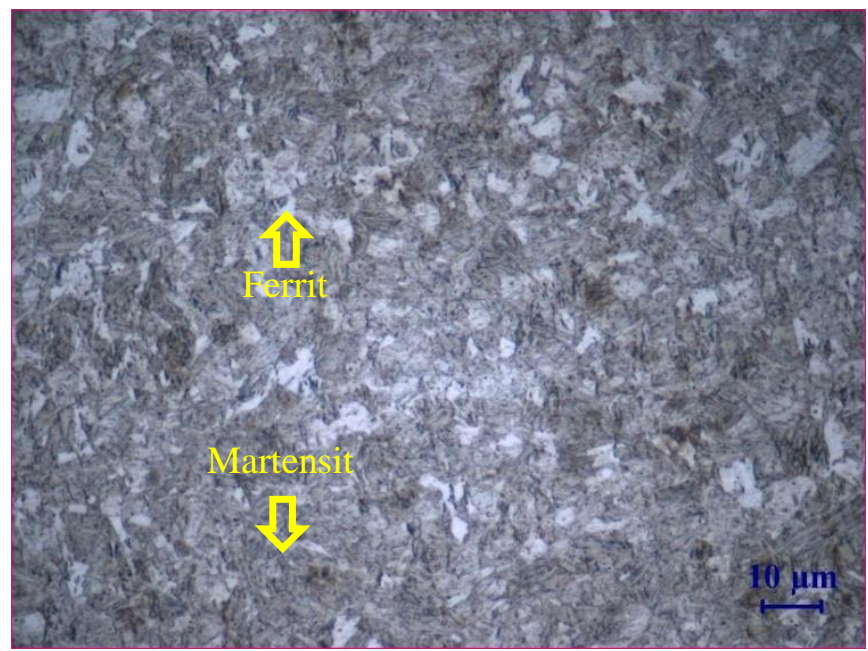

Şekil 1. DP1200 çeliğinin mikroyapısl.

Nokta direnç kaynağı, $8 \mathrm{~mm}$ uç çaplı bakır elektrotlar kullanılarak gerçekleştirilmiştir. Kaynak parametreleri Tablo 2'de gösterilmiştir. Bu çalışmada nokta direnç kaynağının ana değişkenleri olan elektrot basıncı ve kaynak akımının, kaynağın çekme makaslama dayanımı üzerindeki etkisi incelenmiştir. Bu yüzden, kaynak akımı 5 ve $7 \mathrm{kA}$ değerlerinde gerçekleştirilmiş ve elektrot basıncı 26 bar aralığında 1 bar aralıklarla arttırılmıştır. Zaman birimi çevrim cinsindendir ( 1 çevrim=0,02 s).

Tablo 2. Nokta direnç kaynă̆ kaynak parametreleri.

\begin{tabular}{|c|c|c|c|c|c|c|}
\hline $\begin{array}{c}\text { Kaynak } \\
\text { akımı } \\
(k A) \\
\end{array}$ & $\begin{array}{c}\text { Elektrot } \\
\text { basinci } \\
\text { (bar) }\end{array}$ & $\begin{array}{c}\text { İnme } \\
\text { zamanı } \\
\text { (çevrim) }\end{array}$ & $\begin{array}{c}\text { Sikıştırma } \\
\text { zamanı } \\
\text { (çevrim) }\end{array}$ & $\begin{array}{l}\text { Kaynak } \\
\text { zamanı } \\
\text { (çevrim) } \\
\end{array}$ & $\begin{array}{c}\text { Tutma } \\
\text { zamanı } \\
\text { (çevrim) }\end{array}$ & $\begin{array}{c}\text { Ayrılma } \\
\text { zamanı } \\
\text { (çevrim) }\end{array}$ \\
\hline \multirow{5}{*}{5} & 2 & \multirow{6}{*}{15} & \multirow{6}{*}{35} & \multirow{6}{*}{20} & \multirow{5}{*}{10} & \multirow{5}{*}{15} \\
\hline & 3 & & & & & \\
\hline & 4 & & & & & \\
\hline & 5 & & & & & \\
\hline & 6 & & & & & \\
\hline \multirow{5}{*}{7} & 2 & & & & \multirow{5}{*}{10} & \multirow{5}{*}{15} \\
\hline & 3 & \multirow{4}{*}{15} & \multirow{4}{*}{35} & \multirow{4}{*}{20} & & \\
\hline & 4 & & & & & \\
\hline & 5 & & & & & \\
\hline & 6 & & & & & \\
\hline
\end{tabular}

Her parametre için 3 numune olmak üzere çekme makaslama testi ile kaynakların mekanik performansı değerlendirilmiştir. Çekme makaslama testi numunesi boyutları Şekil 2'de gösterilmiştir. Çekme makaslama testleri $2 \mathrm{~mm} /$ dakika çene hızında gerçekleştirilmiştir. Kaynakların mekanik performansı çekme makaslama gerilmesi açısından tanımlanmıştır.

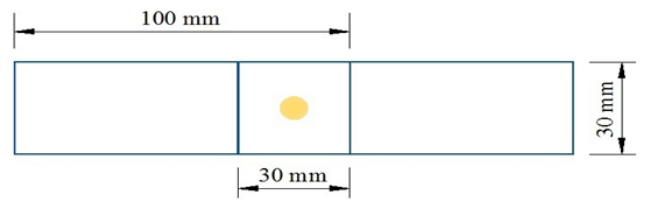

Şekil 2. Çekme makaslama numunelerinin şematik gösterimi. 
Kaynak parametrelerinin çekme makaslama dayanımı üzerine etkisi IBM SPSS STATISTICS 22.0 programında çoklu doğrusal regresyon analizi ile incelenmiştir. IBM SPSS STATISTICS 22.0 programı ve ANOVA analizi literatürde istatistiksel analizlerde tercih edilen ve sağlıklı sonuçlar veren uygulamalar olduğu için bu çalışmada tercih edilmiştir [30], [31]. Yapılan çoklu doğrusal regresyon analizi ile elde edilen korelasyon tablosu ve ANOVA analiz değerleri yorumlanmıştır. Kaynak parametrelerinin önem derecesi belirlenerek, bağımlı değişken (çekme makaslama dayanımı) üzerindeki etkileri karşılaştırılmıştır. Bu doğrultuda kaynak parametrelerinin çekme makaslama gerilmesi üzerindeki etkisini gösteren çoklu doğrusal regresyon modeli oluşturulmuştur.

\section{SONUCLAR VE TARTISMA}

\section{A. ÇEKME MAKASLAMA ÖZELLIKLERİ}

Sonuçlar, kaynak akımı ve elektrot basıncının NDK'lı DP1200 çeliğinin çekme makaslama dayanımları üzerinde önemli bir etkiye sahip olduğunu göstermiştir (Şekil 3). Şekil 3'te verilen grafikte kaynak akımının etkisi değerlendirildiğinde, kaynak akımı arttıkça birleşimlerin çekme makaslama dayanımının arttı̆̆ı görülmektedir. $\mathrm{Bu}$ durum, nokta direnç kaynağında kaynak metalindeki 1sı girdisi ile açıklanmaktadır. Isı girdisi " $\mathrm{Q}=\mathrm{I}^{2}$.R.t" eşitliği ile hesaplanmaktadır. $\mathrm{Bu}$ eşitlikteki $\mathrm{I}=$ akım, $\mathrm{R}=$ toplam direnç ve $\mathrm{t}=$ kaynak süresidir. Eşitlikte görüldüğü gibi akım arttıkça 1S1 girdisi de artmaktadır. Sonuç olarak, kaynak akımı kaynaklı birleşimlerin çekme makaslama dayanımını arttırmaktadır. Elitas vd. [32], Marashi vd. [20], Fukumoto vd. [33] ve Sun vd. [34] benzer çalışmalarında çeşitli malzemelerin nokta direnç kaynağını araştırmışlardır ve kaynak akımının artmasının çekme makaslama dayanımını arttırdığını belirtmişlerdir. Elektrot basıncının etkisi değerlendirildiğinde ise, elektrot basıncı arttıkça 1Sı girdisi arttığı için kritik basınç değerine kadar çekme makaslama dayanımı artmıştır. Fakat kritik değerden daha yüksek elektrot basınçlarında (7 kA kaynak akımında 5 ve 6 bar) aşırı 1sı girdisinden kaynaklanan sıçramalar meydana gelmiştir. Meydana gelen sıçramalar, çekme makaslama dayanımını azaltmıştır. Bu doğrultuda 5 kA kaynak akımında elektrot basıncı arttıkça yük taşıma kapasitesi artmıştır. $7 \mathrm{kA}$ kaynak akımında ise 4 bar elektrot basıncına kadar yük taşıma kapasitesi artmıştır. Daha yüksek elektrot basınçlarında ise çekme makaslama dayanımında düşüş gözlenmiştir. Şekil 3 incelendiğinde optimum çekme makaslama gerilmesi değerinin $7 \mathrm{kA}$ kaynak akımı ve 4 bar elektrot basıncı kaynak parametrelerinde elde edildiği görülmektedir.

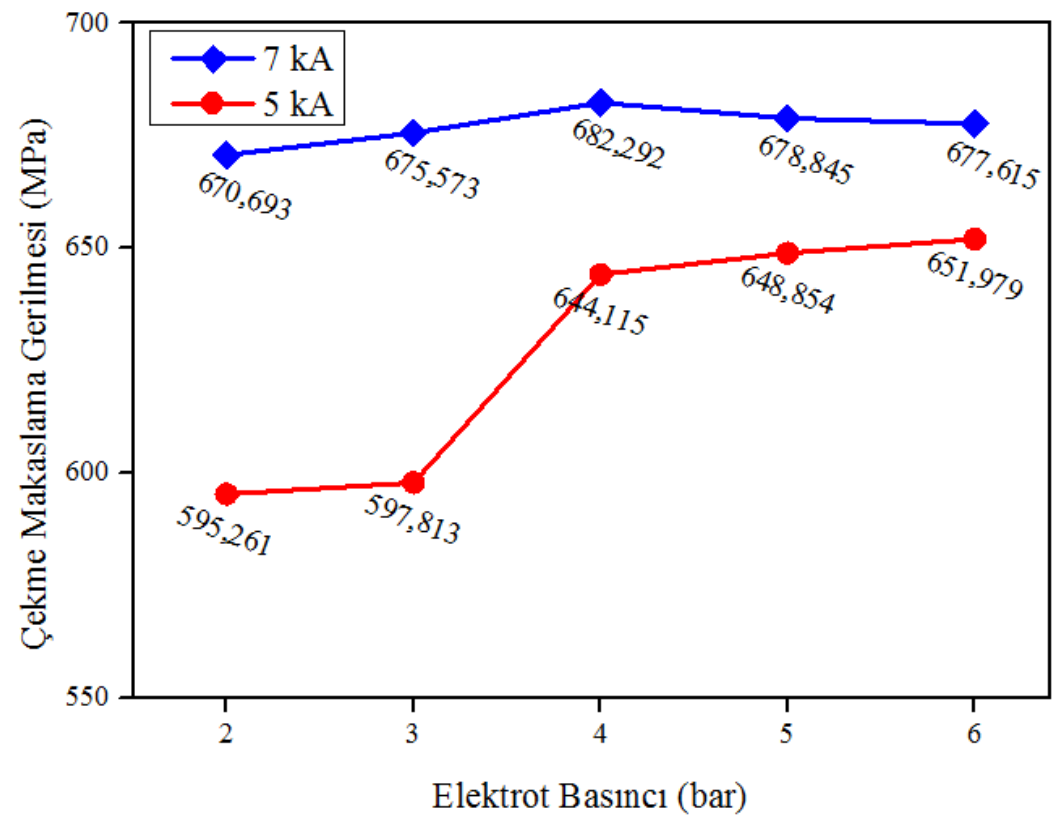

Şekil 3. Farklı kaynak parametrelerinde elde edilen çekme makaslama gerilim değerleri. 


\section{B. ÇOKLU DOĞRUSAL REGRESYON ANALIZZ SONUÇLARI}

IBM SPSS STATISTICS 22.0 programında çalışmadaki bağımlı değişkeni (çekme makaslama gerilmesi) etkileyen iki önemli bağımsız değişken (kaynak akımı ve elektrot basıncı) belirlenmiştir. Kaynak akımı ve elektrot basıncının çekme makaslama gerilmesini etkileme düzeylerini sayısal olarak tespit etmek amacıyla çoklu doğrusal regresyon analizi yapılmıştır. Bu doğrultuda sırasıyla $\mathrm{R}$ değeri ve otokorelasyon durumu incelenmiş olup model için gerekli hipotezler kurulmuştur. ANOVA tablosu ile önem düzeyi değerlendirilmiştir. Kurulan hipotezlerin geçerliliği kontrol edilmiştir. Katsayılar tablosunda bağımsız değişkenlerin bağımlı değişkeni etkileme oranı karşılaştırılmıştır. Sonuç olarak bağımlı ve bağımsız değişkenler arasında çoklu doğrusal regresyon modeli kurulmuştur.

Tablo 3. Model özeti.

\begin{tabular}{cccccc}
\hline Model & $\mathbf{R}$ & $\mathbf{R}^{2}$ & Düzeltilmiş $\mathbf{R}^{2}$ & $\begin{array}{c}\text { Tahminin Standart } \\
\text { Hatası }\end{array}$ & Durbin Watson \\
\hline \multirow{2}{*}{$0,907^{\mathrm{a}}$} & 0,822 & 0,771 & 15,476799 & 1,074 \\
\hline
\end{tabular}

Tablo 3'te $\mathrm{R}$ değeri 0,907 olarak bulunmuştur. $\mathrm{Bu}$ değerin 1'e yakın çıkması modelin geçerlilik düzeyinin yüksek olması anlamına gelmektedir. Analiz çıktıları birbiriyle uyumlu ve anlamlıdır. Hata terimlerinin birbirinden bağımsız olduğu varsayılır. Ayrıca Durbin Watson (DW) katsayısı ile varsayımın testi yapılır. Hata terimlerinin birbirine olan etki sonuçları yani otokorelasyon durumu elde edilmeye çalışılır. DW değeri 0 ile 4 arasında değiş̧mektedir. Tabloda 1,074 DW test değeridir ve bu kabul edilebilir bir değerdir. DW katsayısı için ayrıca $1,5<\mathrm{DW}<2,5$ şartını sağlamadığı için otokorelasyon olduğu da saptanmıştır. Bulunan DW değeri otokorelasyon alt sınırına yakın olduğu için ihmal edilebilir bir değerdir. Bağımsız değişkenlerin, bağımlı değişkeni tahminlediği düşünülen modelde şu hipotezler kurulmuştur:

$\checkmark \quad \mathrm{H}_{0}=$ Model anlamsızdır.

$\checkmark \quad \mathrm{H}_{\mathrm{s}}=$ Model anlamlıdır.

Tablo 4. ANOVA tablosu.

\begin{tabular}{cccccc}
\hline Model & $\begin{array}{c}\text { Kareler } \\
\text { Toplamı }\end{array}$ & $\begin{array}{c}\text { Serbestlik } \\
\text { Derecesi }\end{array}$ & $\begin{array}{c}\text { Karelerin } \\
\text { Ortalaması }\end{array}$ & F & $\begin{array}{c}\text { Önem } \\
\text { Derecesi }\end{array}$ \\
\hline Regresyon & 7749,589 & 2 & 3874,795 & 16,177 & $0,002^{\mathrm{b}}$ \\
\hline Artıklar & 1676,719 & 7 & 239,531 & & \\
\hline
\end{tabular}

Tablo 4'te ANOVA tablosu özeti verilmiştir. F değeri 16,177 ve önem derecesi değeri (p) 0,002 olarak bulunmuştur. Test sonucunda oluşan $\mathrm{p}$ anlamlılık seviyesi 0,05 'ten küçük olduğu için modelin açıklayıcılığ istatistiksel olarak önemlidir ve $\mathrm{H}_{0}$ hipotezi reddedilir. Yani kurulan model anlamlıdır $(\mathrm{p}=0,002<0,05) . \mathrm{H}_{0}$ hipotezinin reddedilmesi modelin anlamlı olduğunu göstermektedir. Regresyon analizinden elde edilen katsayılar tablosu ise Tablo 5 'te gösterilmiştir. 
Tablo 5. Çoklu doğrusal regresyon modeli/bağımsız değişkenler ve katsayıları.

\begin{tabular}{|c|c|c|c|c|c|c|}
\hline \multicolumn{2}{|r|}{ Model } & B & $\begin{array}{l}\text { Standart } \\
\text { Hata }\end{array}$ & $\frac{\text { Standart Katsaylar }}{\text { Beta }}$ & $\mathbf{t}$ & $\begin{array}{l}\text { Önem } \\
\text { Düzeyi }\end{array}$ \\
\hline \multirow{3}{*}{1} & $\begin{array}{l}\text { Sabit } \\
\text { (Çekme } \\
\text { makaslama) }\end{array}$ & 467,787 & $\begin{array}{c}\text { Hata } \\
32,831\end{array}$ & & 14,248 & $\begin{array}{c}\text { Duzeyi } \\
0,000\end{array}$ \\
\hline & $\begin{array}{l}\text { Kaynak } \\
\text { akımı }\end{array}$ & 24,700 & 4,894 & $-0,375$ & 5,047 & 0,001 \\
\hline & $\begin{array}{l}\text { Elektrot } \\
\text { basinc1 }\end{array}$ & 9,080 & 3,461 & $-0,002$ & 2,624 & 0,034 \\
\hline
\end{tabular}

Tablo 5'e göre katsayılar tablosunda B değeri incelendiğinde çekme makaslama gerilmesini etkileyen en önemli değişkenin, kaynak akımı olduğu görülmektedir. Eshraghi vd. [23], Thakur ve Nandedkar [24], X.Q. Zhang vd. [26] benzer çalışmalarında çeşitli malzemelerin NDK işlemini araştırmışlardır ve kaynak akımının çekme makaslama dayanımını etkileyen en önemli parametre olduğunu ifade etmişlerdir. " $t$ " istatistik değerlerine bakıldığında, modeldeki değişkenlerin $\% 5$ anlamlılık düzeyinde anlamlı olduğu görülmektedir.

Pearson korelasyon tablosuna bakıldığında (Tablo 5) bağımlı değişken olan çekme makaslama gerilmesi ile kaynak akımı arasında yüksek düzeyde bir ilişki $(24,700)$ bulunurken, elektrot basınc1 değeri ile çekme makaslama gerilmesi arasında daha düşük düzeyde bir ilişki $(9,080)$ tespit edilmiştir. Bu iki bağımsız değişken için standart hatalar ise kaynak akımı için 4,894 iken, elektrot basıncı için 3,461 bulunmuştur. Kaynak akımının çekme makaslama gerilme değerini etkileme oranının standart hatalar da dahil edildiğinde elektrot basıncına göre daha yüksek olduğu görülmektedir. Bu da kaynak akımının daha kuvvetli bir bağımsız değişken olduğunu göstermektedir. Önem derecelerine bakıldığında bağımlı değişken 0,000 iken; kaynak akımı 0,001 ve elektrot basınc1 0,034 elde edilmiştir. Bu iki bağımsız değişken değerinden ilki (kaynak akımı), bağımlı değişken önem düzeyine daha yakın çıkmıştır. Bu da kurulacak olan modelin anlamlı olduğunu gösteren ve destekleyen bir çıktı olarak bulunmuştur. Elde edilen sonuçlar ışığında çekme makaslama gerilmesi (ÇMG) ve kaynak akımı (KA), elektrot basıncı (EB) arasında kurulan çoklu doğrusal regresyon modeli ise şu şekildedir (Eşitlik 1):

$C \zeta M G=467,787+(24,700 \times K A)+(9,080 \times E B)$

\section{IV.SONUC}

NDK'1ı DP1200 çeliğinin ideal çekme makaslama dayanımını elde etmek için farklı kaynak akımı ve elektrot basıncı parametrelerinin optimizasyonuna odaklanıldığı ve kaynak parametrelerinin çekme makaslama dayanımı üzerindeki etkilerinin çoklu doğrusal regresyon analizi ile incelendiği bu çalışmada elde edilen sonuçlar şu şekildedir:

1. DP1200 çeliğinin düşük miktarda ferrit fazı ve ağırlıklı olarak martensit fazından oluştuğu görülmüştür.

2. Kaynak akımı arttıkça çekme makaslama dayanımı artmıştır.

3. Yüksek kaynak akımı değerinde, elektrot basıncının kritik değerine kadar çekme makaslama dayanımının arttığı, fakat kritik değerinin üzerinde dayanımda düşüş olduğu görülmüştür.

4. Siçrama, çekme makaslama dayanımında düşüşe neden olmuştur.

5. Optimum çekme makaslama gerilmesi $7 \mathrm{kA}$ kaynak akımı ve 4 bar elektrot basıncı kaynak parametrelerinde elde edilmiştir.

6. Çekme makaslama gerilmesini etkileyen en önemli değişkenin kaynak akımı olduğu görülmüştür. 
7. Elde edilen sonuçlar ışığında çekme makaslama gerilmesi değerini etkileyen kaynak akımı ve elektrot basıncı arasında çoklu doğrusal regresyon modeli oluşturulmuştur.

TEŞEKKÜR: $\mathrm{Bu}$ çalışma Karabük Üniversitesi Bilimsel Araştırma Projeleri tarafindan desteklenmiştir (Proje no: KBÜBAP-17-KP-463).

\section{KAYNAKLAR}

[1] R. Roth, J. Clark, and A. Kelkar, "Automobile bodies: can aluminum be an economical alternative to steel," The Journal of The Minerals, Metals \& Materials Society, c. 53, s. 8, ss. 28-32, 2001.

[2] C. C. Tasan, M. Diehl, D. Yan, M. Bechtold, F. Roters, L. Schemmann, C. Zheng, N. Peranio, D. Ponge, M. Koyama, K. Tsuzaki, and D. Raabe, "An overview of dual-phase steels: advances in microstructure-oriented processing and micromechanically guided design," Annual Review of Materials Research, c. 45, s. 1, ss. 391-431, 2015.

[3] M. Pouranvari, "Critical assessment 27: dissimilar resistance spot welding of aluminium/steel: challenges and opportunities," Materials Science and Technology, c. 33, s. 15, ss. 1705-1712, 2017.

[4] B. K. Zuidema, "Bridging the design-manufacturing-materials data gap: material properties for optimum design and manufacturing performance in light vehicle steel-intensive body structures," The Journal of The Minerals, Metals \& Materials Society, c. 64, s. 9, ss. 1039-1047, 2012.

[5] M. Elitaş ve B. Demir, "Elektrot basıncının nokta direnç kaynaklı DP600 çeliğinin mikroyapı ve sertliğine etkileri," Nevşehir Bilim ve Teknoloji Dergisi, c. 7, s. 2, ss. 194-205, 2018.

[6] M. I. Khan, M. L. Kuntz, E. Biro, and Y. Zhou, "Microstructure and mechanical properties of resistance spot welded advanced high strength steels," Materials Transactions, c. 49, s. 7, ss. 16291637, 2008.

[7] X. Long, and S. K. Khanna, "Fatigue properties and failure characterization of spot welded high strength steel sheet," International Journal of Fatigue, c. 29, s. 5, ss. 879-886, 2007.

[8] C. Ma, D. L. Chen, S. D. Bhole, G. Boudreau, A. Lee, and E. Biro, "Microstructure and fracture characteristics of spot-welded DP600 steel," Materials Science and Engineering: A, c. 485, s. 1-2, ss. 334-346, 2008.

[9] C. Lindgren, J. O. Sperle, and M. Jonsson, "Fatigue strength of spot welded beams in high strength steels," Welding in the World, c. 37, s. 1, ss. 90-104, 1996.

[10] O. Holovenko, M. G. Ienco, E. Pastore, M. R. Pinasco, P. Matteis, G. Scavino, and D. Firrao, "Microstructural and mechanical characterization of welded joints on innovative high-strength steels," La Metallurgia Italiana, c. 105, s. 3, ss. 3-12, 2013.

[11] T. K. Pal, and K. Bhowmick, "Resistance spot welding characteristics and high cycle fatigue behavior of DP 780 steel sheet," Journal of Materials Engineering and Performance, c. 21, s. 2, ss. 280-285, 2012.

[12] M. Elitas, and B. Demir, "Residual stress evaluation during RSW of DP600 sheet steel," Materials Testing, c. 62, s. 9, ss. 888-890, 2020. 
[13] A. Ghaheri, A. Shafyei, and M. Honarmand, "Effects of inter-critical temperatures on martensite morphology, volume fraction and mechanical properties of dual-phase steels obtained from direct and continuous annealing cycles," Materials \& Design (1980-2015), c. 62, ss. 305-319, 2014.

[14] N. Farabi, D. L. Chen, and Y. Zhou, "Fatigue properties of laser welded dual-phase steel joints," Procedia Engineering, c. 2, s. 1, ss. 835-843, 2010.

[15] M. Sarwar, and R. Priestner, "Influence of ferrite-martensite microstructural morphology on tensile properties of dual-phase steel," Journal of Materials Science, c. 31, s. 8, ss. 2091-2095, 1996.

[16] M. A. Erden, "The effect of the sintering temperature and addition of niobium and vanadium on the microstructure and mechanical properties of microalloyed PM steels," Metals, c. 7, s. 9, ss. 329, 2017.

[17] F. Hayat, B. Demir, and M. Acarer, "Tensile shear stress and microstructure of low carbon dual phase Mn-Ni steels after spot resistance welding," Metal Science and Heat Treatment, c. 49, s. 910, ss. 484-489, 2007.

[18] M. Pouranvari, and S. P. H. Marashi, "Critical review of automotive steels spot welding: process, structure and properties," Science and Technology of welding and joining, c. 18, s. 5, ss. 361403, 2013.

[19] N. J. Den Uijl, "Resistance spot welding of advanced high strength steels," Ph.D. dissertation, Department of Materials Science and Engineering, Delft University, Delft, Netherland, 2015.

[20] P. Marashi, M. Pouranvari, S. Amirabdollahian, A. Abedi, and M. Goodarzi, "Microstructure and failure behavior of dissimilar resistance spot welds between low carbon galvanized and austenitic stainless steels," Materials science and engineering: A, c. 480, s. 1-2, ss. 175-180, 2008.

[21] M. Pouranvari, A. Abedi, P. Marashi, and M. Goodarzi, "Effect of expulsion on peak load and energy absorption of low carbon steel resistance spot welds," Science and Technology of Welding and Joining, c. 13, s. 1, ss. 39-43, 2008.

[22] M. Pouranvari, S. P. H. Marashi, and D. S. Safanama, "Failure mode transition in AHSS resistance spot welds. Part II: Experimental investigation and model validation," Materials Science and Engineering: A, c. 528, s. 29-30, ss. 8344-8352, 2011.

[23] M. Eshraghi, M. A. Tschopp, M. A. Zaeem, and S. D. Felicelli, "Effect of resistance spot welding parameters on weld pool properties in a DP600 dual-phase steel: a parametric study using thermomechanically-coupled finite element analysis," Materials \& Design (1980-2015), c. 56, ss. 387-397, 2014.

[24] A. G. Thakur, and V. M. Nandedkar, "Optimization of the resistance spot welding process of galvanized steel sheet using the Taguchi method," Arabian Journal for Science and Engineering, c. 39, s. 2, ss. 1171-1176, 2014.

[25] U. Esme, "Application of taguchi method for the optimization of resistance spot welding process," The Arabian Journal for Science and Engineering, c. 34, s. 2, ss. 519-529, 2009.

[26] X. Q. Zhang, G. L. Chen, and Y. S. Zhang, "Characteristics of electrode wear in resistance spot welding dual-phase steels," Materials \& Design, c. 29, s. 1, ss. 279-283, 2008. 
[27] H. Aydin, "The mechanical properties of dissimilar resistance spot-welded DP600-DP1000 steel joints for automotive applications," Proceedings of the Institution of Mechanical Engineers, Part D: Journal of Automobile Engineering, c. 229, s. 5, ss. 599-610, 2015.

[28] X. Luo, J. Ren, D. Li, Y. Qin, and P. Xu, "Macro characteristics of dissimilar high strength steel resistance spot welding joint," The International Journal of Advanced Manufacturing Technology, c. 87, s. 1-4, ss. 1105-1113, 2016.

[29] A. G. Thakur, T. E. Rao, M. S. Mukhedkar, and V. M. Nandedkar, "Application of Taguchi method for resistance spot welding of galvanized steel," ARPN Journal of Engineering and Applied Sciences, c. 5, s. 11, ss. 22-26, 2010.

[30] T. Ersöz, M. T. Elitaş ve F. Ersöz, "Oecd ülkelerinde biyokütle enerji üretiminin çok boyutlu ölçekleme analizi ile incelenmesi,” TÜBAV Bilim Dergisi, c. 8, s. 3, ss. 1-11, 2015.

[31] I. Ciftci, and H. Gokce, "Optimization of cutting tool and cutting parameters in machining of molybdenum alloys through the Taguchi method," Journal of the Faculty of Engineering and Architecture of Gazi University, c. 34, s. 1, ss. 201-213, 2019.

[32] M. Elitas, and B. Demir, "The effects of the welding parameters on tensile properties of RSW junctions of DP1000 sheet steel," Engineering, Technology \& Applied Science Research, c. 8, s. 4, ss. 3116-3120, 2018.

[33] S. Fukumoto, K. Fujiwara, S. Toji, and A. Yamamoto, "Small-scale resistance spot welding of austenitic stainless steels," Materials Science and Engineering: A, c. 492, s. 1-2, ss. 243-249, 2008.

[34] D. Q. Sun, B. Lang, D. X. Sun, and J. B. Li, "Microstructures and mechanical properties of resistance spot welded magnesium alloy joints," Materials Science and Engineering: A, c. 460-461, ss. 494-498, 2007. 